\title{
Mobility haunted by class? Book review: Stepping Into the Elite: Trajectories of Social Achievement in India, France, and the United States by Jules Naudet. Oxford University Press, 2018
}

\author{
Zsuzsanna Árendás ${ }^{1}$ \\ https://doi.org/10.51624/SzocSzemle.2021.3.7 \\ Manuscript received: 26 October 2020. \\ Revised manuscript received: 16 December 2020 \\ Acceptance of manuscript for publication: १८ December 2020.
}

Social mobility is a fascinating terrain of sociological investigations; nevertheless, a complex study on the narratives of protagonists of such 'journeys' is even more intriguing due to the insiders' gaze, and how it informs the existing scholarship on the organizing principles and boundary-making processes of a society. In the age of polices brutalities against Afro Americans and the following Black Lives Matter movement in the US, last year's Yellow vest protests in France, or the resurgent outcries of Dalit activists and the related street fights in Delhi and other Indian cities triggered by the physical brutalities of upper class men against Dalit women, prove that the theme is more relevant than ever.

The French sociologist, Naudet's book analyzes narratives of social mobility of individuals who experienced first-generation steep upward mobility, moving from 'rugs to the riches' in three national contexts. India, France and the US, represent three different types of social stratification, understandings on class and mobility: these are presented in the book as a closed society (India), a class society (France) and an open society (the US) based on the structure of a society and the (non-)permeability of its class borders.

Departing from Durkheim's (1952) thoughts on anomie, a concept describing consequences of a sudden social change and Sorokin's (1927) ideas that rapid social mobility leads to identity crisis and mental disorders, Naudet critically investigates diverse narratives of social mobility. For the author of the book, the main question is to obtain a better understanding of the individual coping strategies of success related to upward social mobility, rather than focusing merely on the tensions, identity crisis and costs of social mobility, this way broadening his research interest into new directions.

1 Institute for Sociology, Research Centre for Social Sciences, Hungarian Academy of Sciences, email: arendas.zsuzsanna@tk.hu 
The book is based on a cross-national empirical study carried out between 2004 and 2009, including over 150 interviews. The interviews were conducted with children of low-skilled workers who became senior bureaucrats (civil servants of the state bureaucracy), academics, top managers of private or national companies and other leading professionals in their adulthood. The research investigated individual upward mobilities, analyzing the interviewees' personal narratives and reflections. The research presumed that the national contexts may play an important role in these narratives, both in terms of their dominant class structure and opportunities (or barriers) they provide for social mobility, and the offered understandings on social change itself.

While moving across different national contexts, the concept of 'instituted ideology' offers a firm comparative analytical framework. It combines multiple scales of country, neighborhood, family, school, social class, minority status, caste, origin and so on. Instituted ideology refers to the high congruence of ideology(ies) on various levels, where a strong presence of it on one level results in its dominance in another segment too. Thus, when experiencing upward social mobility, in case of instituted ideology of success, an individual can formulate a narrative of success and experiences continuity between his/her background of origin instead of a sense of rupture.

In the Indian case, upward social mobilities are presented through narratives of successful individuals coming from the Dalit community ${ }^{2}$. The Indian case is specific among the three country examples due to the fuzzy principles defining social status of an individual: on one hand it is prescribed by the fixed Stand in the Weberian sense of the caste (one is born into it and dies in it), on the other hand by professional success and prestige of one's profession. The predominance of caste in defining one's social status (over professional attainment) may very across different social settings and situations- profession may weight increasingly more, but one's caste origin can never be overruled. Therefore, 'social mobility' in the Indian context refers to the change in social position in respect to the profession (not the caste).

The interviews conducted among successful Dalits in India represent a rich ethnographic material, revealing that they define themselves in opposition to the dominant casts (upper class Hindus) in a form of a counter-ideology, and have internalized a strong sense of solidarity with their community of origin, including a moral obligation to 'give back'. While experiencing steep upward social mobility, the Dalits in India maintain strong bonds with their community of origin with regular references to the political program of Ambedkar, and to the counter-cultural ideology positioned against the upper classes. This political stance provides a sense of firm identity and gives a clear indication on how to relate to the group of origin. Naudet also point to interesting sectoral differences: in the state bureaucracy and the academic field, the tension between the new attained social position and the background of

2 A political community, which emerged from the Arya Samaj Hindu reformist movement and from Dr. Ambedkar, the author of the modern Indian Constitution, the enigmatic figure of the freedom fight against untouchability and for higher social justice in India. 
origin is more easily reconciled through the solidarity and 'giving back' ideology than among individuals working in the business sector in high managerial positions.

Unlike in most cases of Dalit narratives from India, in the French case, the individual narratives are characterized by a perceived difference between the group of origin and the attained new social group, resulting in a feeling of not belonging either here nor there (loosing attachments to the former and not able to fully arrive to the other). As the author states, the French discourse is often marked by narratives of social mobility closely linked to mastering (or inability to master) the socio-cultural 'codes' of the high society, and 'unlearning' the codes (un-culturation) related to the humble background of family often associated with working class culture and socialization. In this complex process of deculturation and acculturation, the book points to specific educational institution, which 'do the job'. Some of the French interviewees reflect on the 'hidden agenda' of these top universities and grand écoles in this respect, making their students to internalize certain codes of conduct, behaviours, use of language etc. Not mastering such codes or not well-mastering them quickly creates a sense of not belonging in the upwardly mobile individuals, as it is pointed out by many French interviewees. For some of the interviewees belonging to racialized minorities in France, the sense of dislocation was stronger than in case of their counterparts with a White working-class background. For some, the Republican model helps in making sense of their own difference and provides the idea that in the French republic race is insignificant. As Naudet points out, this is a double-edged sword as while offering a colour-blind approach, emphasizing merit and nothing else, the French republican deal obliges the individual not to emphasize her own difference (even if this difference is perceived as a daily experience). This disables the effected individuals to make sense of their 'difference gap' as the author points out. The author also notes a generational difference, as part of which interviewees belonging to the younger generation of immigrant background tend to emphasize their' diversity' more, which also means the weakening of the Republican model of integration and more space for diversity-based narratives, and demands.

While the US stands for an open society with low barriers to social mobility, race continues to play a key importance. The American society is based on the thesis of American exceptionalism unique to the US described in detail earlier by Lipset and Tocqueville. The comprehensive high school system in the US, as pointed out earlier by Turner (vocational and academic disciplines are taught in an integrated manner in the same institution), contributes to the reduction of social class distance (unlike in France, or other countries of early school selection). Avoiding this early school selection clearly contributes to the ideology of meritocracy in the American society, namely that 'anyone can make it' in the country of opportunities. Nevertheless, the US university system is deeply structured and class-based, reproducing the existing status quo regarding class divisions. Paradoxically, the American education system through creating the illusion of classless society seriously contributes to the legitimization of 
social inequalities. Thus, despite the 'competitive system' as an inherent feature of the US society (according to which merit and individual strive are decisive), American interviews reveal a strong tension between the group of origin and the new attained social position due to the cognitive dissonance between the American ethos and the lived experience of inequality. Naudet's most important parts of the analysis of the US case focus on racial minorities, and are meant to understand the interplay of class and racial difference when understanding social mobility. Here, unlike in France, the question of cultural legitimacy is far less important, instead, the social status is mainly linked to economic capital and emerges from class position. The US minority examples, more precisely, the Afro American case proves that relating back to the group of origin is important but 'looking ahead' is even more. If circumstances permit, one needs to 'reach out' to the group of origin without the strong ideological commitment and militant political ideology of the Dalit movement in India. It remains to be seen if the Black lives Matter movement will alter these elite attitudes in the US, making these voices more political or militant on a long run.

The analysis of the 'minority cases' from all the three countries informs the rapidly growing scholarship on a specific type of inequalities, namely those based on race, which are in most cases combined with class-related inequalities, facing social discrimination and multiple injustices while becoming upward mobile. Solidarity towards own group turns out to be a general reaction in all the three types of minorities either via 'paying back to society' (Dalits), 'reaching back to the group of origin' (African Americans) or 'giving back' to one's parents in case of North African immigrants. This behaviour forms the backbone of a 'minority culture of mobility' encountered through the research across the three fields in cross-national contexts. Naudet's book is enriched with plenty of interview excerpts and ethnographic observations of the author from the three fields, making the theoretical arguments not only convincing, but strongly connected to the empirical parts of his work.

Beside the global topical relevance of the book (BLM movement and other similar social movements), it is unavoidable to emphasize the direct link of this book to the CEE region and most importantly, to its racialized minorities, such as the Roma population. In the last 25 years after the Cold War, a new generation of young Roma elite has emerged in this region. How do they cope with their success on an individual level? What social barriers do they perceive? And most importantly, what is the socio-political role they envision for themselves, if any? These questions are yet to be answered.

\section{References}

Durkheim, Émile (1952) Suicide: A Study of Sociology. London: Routledge. Sorokin, Pitirim (1927): Social Mobility. New York: Harper and Brothers. 